\title{
Nanoparticles in the soil environment and their behaviour : An overview
}

\author{
Rakesh $\mathrm{K}_{\text {umar }}{ }^{1}, \mathrm{~K}_{\text {ishan Singh Rawat }}{ }^{*}$ and $\mathrm{A}$ nil K umar M ishra ${ }^{2}$ \\ ${ }^{1}$ Division of Agricultural Physics, Indian Agricultural Research Institute, New Delhi-110012, INDIA \\ ${ }^{2}$ Water Technology Centre, Indian Agricultural Research Institute, New Delhi-110012, INDIA \\ *Corresponding author. E-mail: ks_rawat2002@yahoo.com \\ Received: March 29, 2012; Revised received: J une 5, 2012; Accepted: J uly 7, 2012
}

\begin{abstract}
The increasing use of nanoparticles (NPs) in industries, soil and water remediation technologies, potential agricultural uses (e.g. fertilizers) and unintentional releases via air, water and sewage sludge application to the land likely leads to the release of such materials into the environment. The unique properties of NPs, such as high specific surface area, abundant reactive sites on the surface as a consequence of a large fraction of atoms located on the exterior rather than in the interior of NPs, as well as their mobility, could cause environmental hazards or potentially harm soil health.It could be assumed that NPs may not have a direct influence on plant growth but may be responsible for the influence through indirect mechanisms. Light microscopy of root sections showed that the $\mathrm{ZnO}$ particles adsorbed into root tissues and cells and damaged the root tissues. Results from ecotoxicological studies show that certain NPs have effects on organisms under environmental conditions, though mostly at elevated concentrations. Nanominerals and mineral NPs in the environment have been present throughout the evolutionary development of hominids, and our exposure to these through inhalation, ingestion are important foci of nanotoxicology and environmental sciences. The more research on occurrence, characteristics of NPs and their behaviour in environment is needed towards a logical conclusion of the effects of NPs on environment.
\end{abstract}

Keywords: Nanoparticle, Nanoparticle behaviour, Occurrence, Soil environment

\section{INTRODUCTION}

Nanoscience and nanotechnology have become the "buzz words" among the soil scientific community at the start of the twenty-first century. Is this just nanohype, or are nanoscience and technology truly revolutionary? And, if so, what importance do they have to soil environment and related fields? Because of new advances in instrumentation and theory, scientists have come to realize that within the range of 1 to as much as $100 \mathrm{~nm}$, often referred to as the nanoscale, materials may display physical properties and chemical behaviors that are unique and often cannot be described by chemistry and physics of bulk systems. Nanoscale size may lead to different crystalline order or structure, different stability and chemical reactivity, and unique thermal, electrical, optical, tensile strength, and/or magnetic properties than observed in either molecules or larger scale (bulk) materials. The ability to probe structure and behavior of nanoparticles is truly a revolution because it is a view into a previously unexplored world. The field of nanoscience is of crucial importance to the agricultural sciences especially soil science because many of the natural components of soils are nanoparticulate or contain nanoscale features.

Today, nanoscale materials find use in a variety of different areas such as electronic, biomedical, pharmaceutical, cosmetic, energy, environmental, catalytic and material applications. Because of the potential of this technology there has been a worldwide increase in investment in nanotechnology research and development (Guzman et al., 2006). Data on the current use and production of NP are sparse and often conflicting. One estimate for the production of engineered nanomaterials was 2000 tons in 2004, expected to increase to 58,000 tons in 2011 (Maynard et al., 2006).

\section{NANOPARTICLES AND NANOMINERALS}

Within an Earth science context, Banfield and Zhang, (2001) suggested that nanoparticles might be defined based on the size at which fundamental properties differ from those of the corresponding bulk material. According to such a definition, the size range that constitutes a nanoparticle will vary for different materials, but current evidence suggests that this size range often is between roughly $1 \mathrm{~nm}$ and a few to several tens of nanometers for Earth materials (Hochella et al., 2008). The size range of nanoparticles versus other particles of environmental interest is shown in Fig. 2. Viruses and many inorganic colloids qualify are nanoparticles.

Although bacteria are much too large to be considered nanoparticles, they may produce nanoscale biominerals. It is important to note that nanoparticles are often aggregated into colloidal or larger grains, which can greatly affect their properties with respect to, for example, transport, reactivity, and other geochemical

ISSN : 0974-9411 (Print), 2231-5209 (Online) All Rights Reserved ๔ Applied and Natural Science Foundation www.ansfoundation.org 


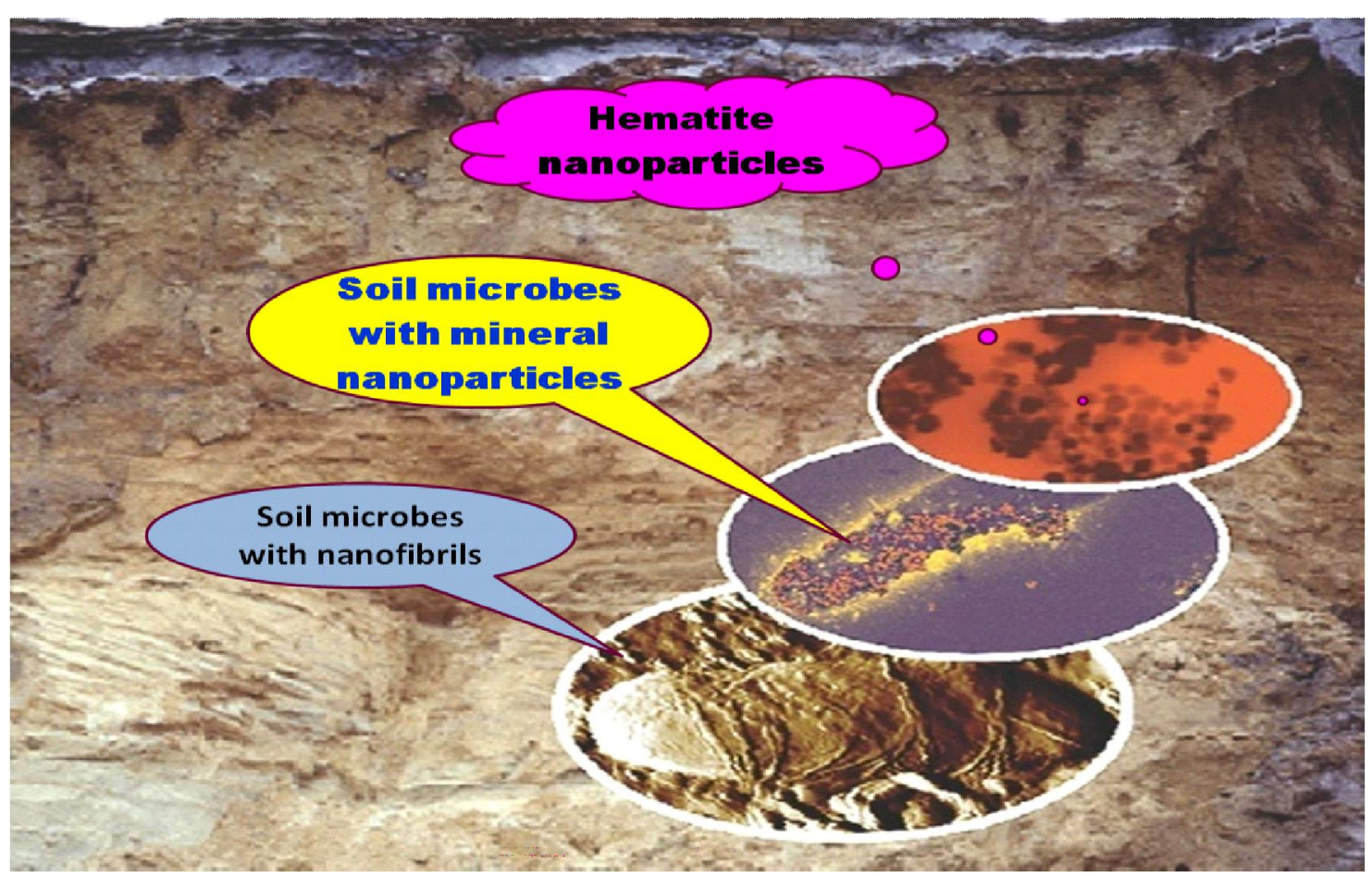

Fig. 1. Soil environments contain a wealth of nanoparticles, and understanding nanoparticle behaviour is a key to a wide variety of soil processes. This figure showing a soil microbe with nanofibrils, a soil microbe with mineral nanoparticles and nanoparticles of hematite (Source: M aurice and H ochella, 2008).

characteristics. Hochella et al. (2008) defined nanominerals as minerals such as ferrihydrite that only exist in the nanoparticle size range, or clays that only exist with at least one dimension in that size range, whereas mineral nanoparticles are minerals that are in the nanosize range, but also exist at larger sizes. The fact that nanominerals and mineral nanoparticles may have properties, including stability and reactivity, that change as a function of size makes them fundamentally distinct from larger scale materials.

Occur rence: Our knowledge on the occurrence of MNPs in the environment is very little due to lack of identification and quantification techniques of MNPs hinder. Currently, investigators applied simple algorithms to predict the amount of MNPs to the environment. Very high concentrations of Latex, $\mathrm{ZnO}$, and $\mathrm{TiO} 2$ are expected in soil and water (Boxall et al., 2008; Fig. 3). The expected MNP concentrations in soil are 40 times higher than those in water. The highest concentrations for MNP are Latex, $\mathrm{ZnO}$, and $\mathrm{TiO} 2$, because of their wide applications. Gottschalk et al. (2009) also calculated environmental concentrations of MNPs in different environmental media based on a probabilistic material flow analysis. More accurate estimation is still unavailable because of the absence of proper quantitative methods.

Classification of nanoparticles: According to different criteria (sources, bulk materials, and sizes), NPs could be classified. The first level of NP classification will be based on their sources. Depending on their sources, NPs could be divided into NNPs and anthropogenic NPs (ANPs). Natural NPs are classified as biogenic, geogenic (including burning of geogenic sources), and atmospheric NPs which present in the environment for a long period of time. Anthropogenic NPs contains two categories, namely accidental NPs and manufactured NPs. MNPs are the major constituent of ANPs. According to their matrix materials, MNPs could be divided into the following groups: carbon-based NPs (such as carbon nanotubes (CNTs) and fullerene), metal-based NPs (such as nanogold and nano-zero-valent iron), oxide-based NPs (such as nano silver oxide, nano titanium oxide, nano zinc oxide, and silicon oxide), and polymer-based NPs (such as polyethyleneglycol). During manufacturing and human daily activities, such as cooking, electricity generation, industrial boiling, diesel burning, and welding, NPs may be accidentally produced and discharged into the environment (Murr et al., 2004) and known as accidental NPs.

Why nanoparticles behave differently?: One of the principal ways in which a nanoparticle differs from a larger or bulk material is that a high proportion of the atoms that are associated with a nanoparticle occur at the surface. It is also well established that the surface structure of a mineral can be different from the bulk structure in terms of the atomic coordination environments. The lack of full coordination at a surface leads to the phenomena known as surface relaxation and reconstruction. Surface relaxation is the movement of 


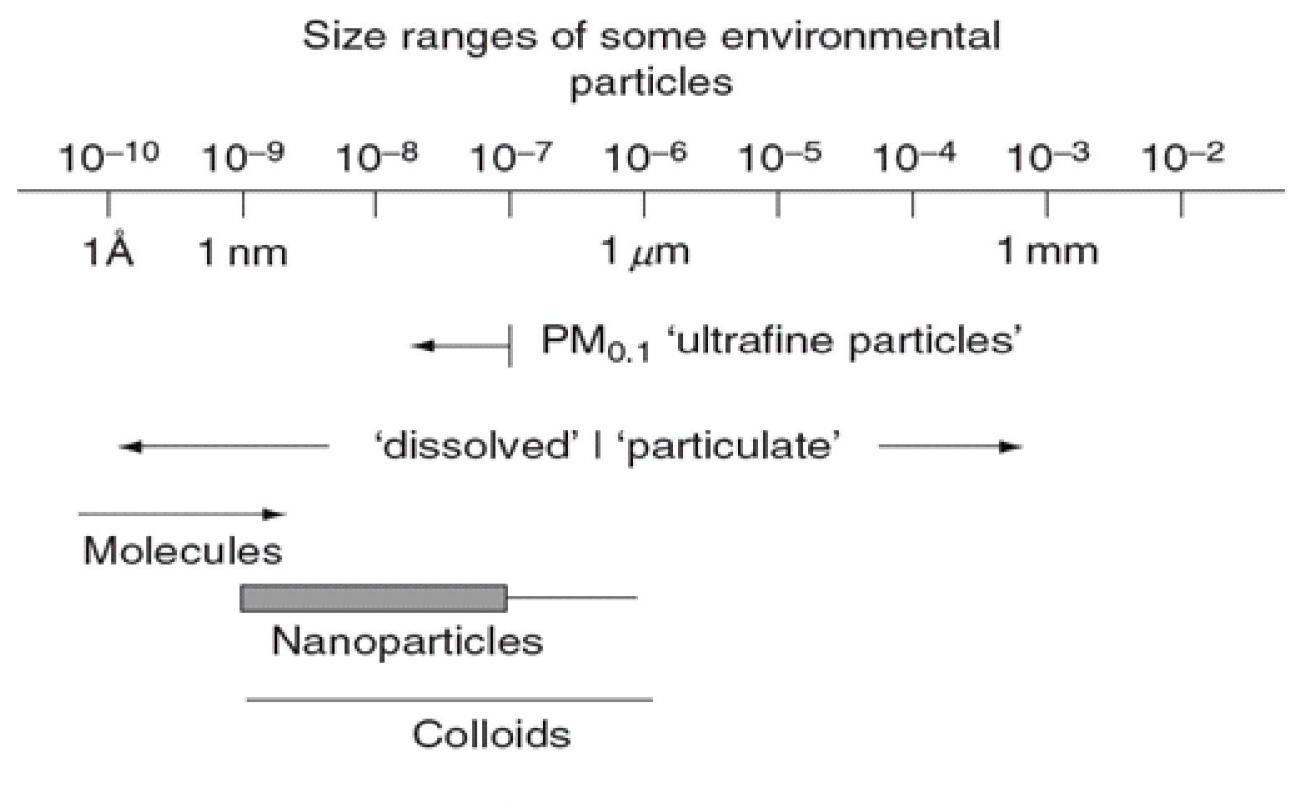

Viruses

Bacteria

Sand

Fig. 2. The size ranges of some environmental particles, including nanoparticles. The box for nanoparticles indicates that nanoparticles are $100 \mathrm{~nm}$ or less in at least two dimensions, but can be longer in the third dimension (such as nanotubes and nanowires) (Source: M aurice and $\mathrm{H}$ ochella, 2009).

atoms at a surface in vacuum in response to dangling bonds. Relaxation may also occur on hydrated surfaces (Eng et al., 2000) as it occurs in air or aqueous solution. surface reconstruction is the process by which atoms at the surface of a crystal assume a different structure than that of the bulk in order to make up for lack of full bonding that would occur in the bulk solid. Surface reconstruction often results in a different unit cell at the surface than in the bulk solid.

In addition to two factors, nanoparticles may have different surface composition, different types and densities of sites, and different reactivity's with respect to processes such as adsorption and redox reactions (Waychunas et al., 2005). For NPs size quantization of the electron structure, coupled with changes to surface structure and surface defect site density, may lead to different rates of electron transfer in redox reactions (Madden and Hochella, 2005).

According to classical theory of mineral nucleation (Neilson, 1964), the free energy of formation of a single crystal ("Gn):

\section{$\Delta \mathrm{Gn}=\Delta \mathrm{Gbulk}+\Delta \mathrm{Ginterf}$}

is the sum of the change in bulk free energy ("Gbulk) coupled with the change in free energy that occurs upon formation of a new interface ( $\Delta$ Ginterf). For crystals larger than about $2 \mathrm{~mm}, \Delta$ Ginterf $<<\Delta$ Gbulk and can be ignored (Berner, 1980). However, for smaller crystals, $(\Delta$ Ginterf must be taken into consideration, and this has very important implications for crystal nucleation kinetics. In order for a particle to nucleate, it must overcome a significant energy barrier associated with the formation of surface area; this is considerably easier to accomplish when the system is highly supersaturated (highly favorable $\Delta$ Gbulk) and helps to explain why minerals may nucleate homogeneously from solution at high supersaturation. But at low supersaturation, particles nucleate only heterogeneously on a previously existing surface. For each saturation state, there is a critical nucleus size that a nucleating crystal must attain before it is stable and can continue to grow.

Nanoparticles pathways from anthroposphere into envir onment: Release of NP may come from point sources such as production facilities, landfills or wastewater treatment plants or from nonpoint sources such as wear from materials containing NPs (Fig. 6). Accidental release during production or transport is also possible. In addition to the unintentional release there are also NP released intentionally into the environment. Whether the particles are released directly into water/soil or the atmosphere, they all end up in soil or water, either directly or indirectly for instance, via sewage treatment plants, waste handling or aerial deposition.

In the soil environment the formation of aggregates and therefore of larger particles that are trapped or eliminated 


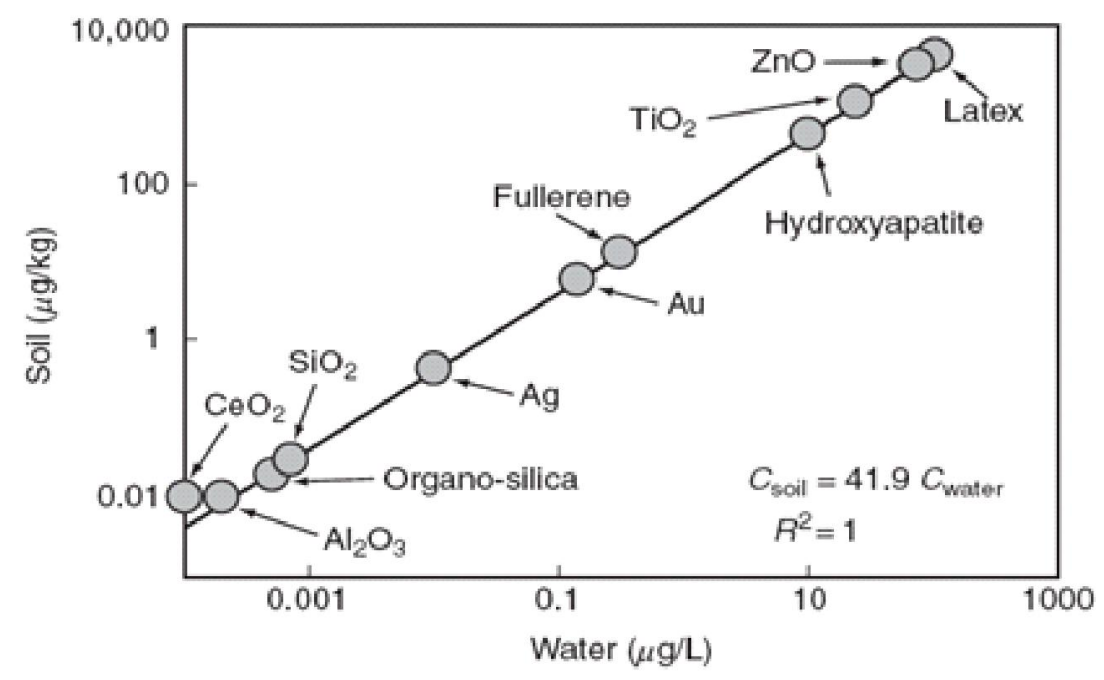

Fig. 3. Predicted M N P concentrations in water and soil (Source: Boxall et al., 2008).

through sedimentation affects the concentrations of free NP (Fig. 7). Humans can be either directly influenced by NPs through exposure to air, soil or water or indirectly by consuming plants or animals which have accumulated NPs. Aggregated or adsorbed. Whereas the possibility of biomagnification of NP in the food-chain has been mentioned (EPA, 2009), no data are currently available. NPs will experience abiotic interactions because the conditions prevailing in the different atmospheric, aquatic and terrestrial environments, leading to physical and chemical alterations (Fig. 7). These alterations will greatly determine the fate of the NPs in the environment and thus their bioavailability to organisms. Once in the proximity of organisms, interactions might occur at biological interfaces, resulting in the entrance of NPs into these organisms. Once inside the organisms, NPs may cause various toxic effects and might be transferred through food webs, thus affecting communities and ecosystems.

Among other impacts, ENPs' effects on photosynthetic organisms may reduce the fixation of $\mathrm{CO}_{2}$; ENPs adsorbed or deposited; on photosynthetically active surfaces might reduce light availability or gas exchange; and thus photosynthesis; ENPs present in the atmosphere might increase the nuclei available for raindrop formation; thus altering precipitation; ENPs' impacts on bacteria, fungi, and other edafic fauna; might affect soil respiration; and other soil-texture-related processes such as transport of liquids; or gases; also modifying symbiotic relationships. Together, this might lead to impairments in three key services provided by ecosystems, i.e., nutrient cycling; water depuration; and biomass production (Navarro et al., 2008).

\section{NANOPARTICLES IN SOIL ENVIRONMENT}

Nanoparticles in soil participate in essential ecological services as, regulating water storage and element cycling, Sorbing and transporting chemical and biological contaminants, serving as a source or sink of organic carbon and plant nutrients etc. (Theng, 2008). NPs formed in soil environment mainly through, inheritance (from preexisting parent rocks and other weathered materials), transformation (where the overall layer structure is retained but the interlayer region is markedly altered), neoformation (by precipitation or crystallization from solution or a gel precursor) and as we know bacterial cells are efficient accumulators of metal cations, which then combine with anions $\left(\mathrm{CO}_{3}^{-2}, \mathrm{PO}_{4}^{-3}\right.$, silicate) from the surrounding medium to form a variety of nanosize minerals. Bacteria can also oxidize or reduce metals.

Simultaneous functioning of various mechanisms: Adsorption mechanisms should also compare the adsorption systems at different $\mathrm{pHs}$ because $\mathrm{pKa}$ of organic chemicals and pHzpc of MNPs can affect the magnitude of adsorption. Different adsorption mechanisms may contribute at different $\mathrm{pHs}$ as presented in Fig. 9. At $\mathrm{pH}>\mathrm{pHzpc}$ or $\mathrm{pH}<\mathrm{pKa}$, the electrostatic repulsion decreases the adsorption as $\mathrm{pH}$ increases (when $\mathrm{pH}>\mathrm{pHzpc}$ ) or $\mathrm{pH}$ decreases (when $\mathrm{pH}<\mathrm{pKa}$ ). But at $\mathrm{pKa}<\mathrm{pH}<\mathrm{pHzpc}$, electrostatic attraction is an important interaction mechanism.

In addition, in this $\mathrm{pH}$ range, cation exchange, hydrophobic interaction, hydrogen bond and $\mathrm{p}-\mathrm{p}$ interaction could all contribute to the overall adsorption. Hydrogen bond is considered as an attractive force between a hydrogen atom and an electronegative atom. At $\mathrm{pHs}$ higher than $\mathrm{pKa}$ of organic chemicals and $\mathrm{pHzpc}$ of MNPs, both organic chemicals and MNPs are deprotonated, and thus hydrogen bond is negligible. Therefore, lack of $\mathrm{pH}$-dependent adsorption is an evidence of minimal contribution of hydrogen bond (Chen et al, 2007). If the adsorption is controlled by hydrophobic interaction, CNT oxidation will decrease the adsorption. However, if the adsorption is controlled by hydrogen bond, CNT oxidation will increase the 


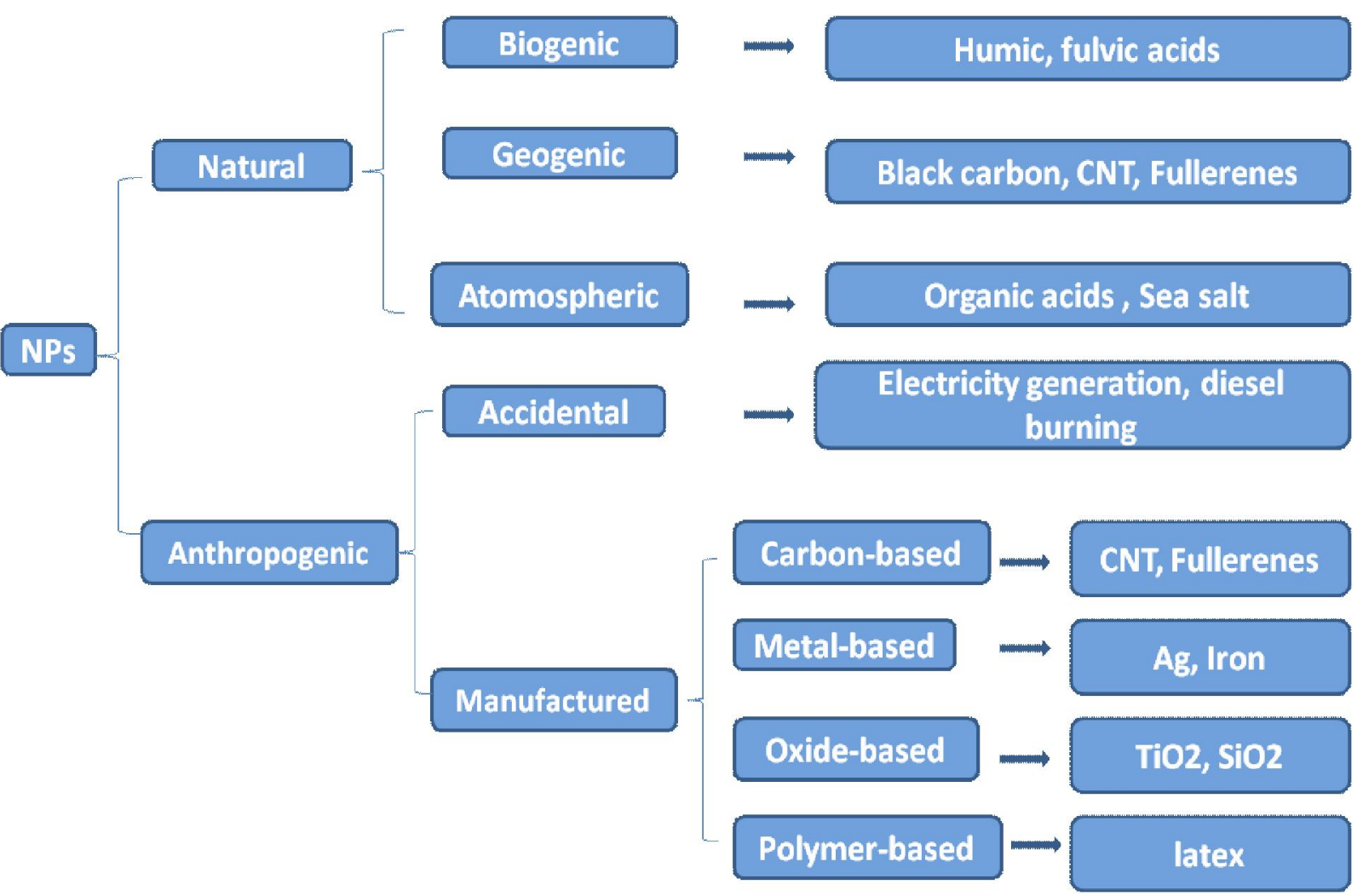

Fig. 4. Classification of nanoparticles (NPs).

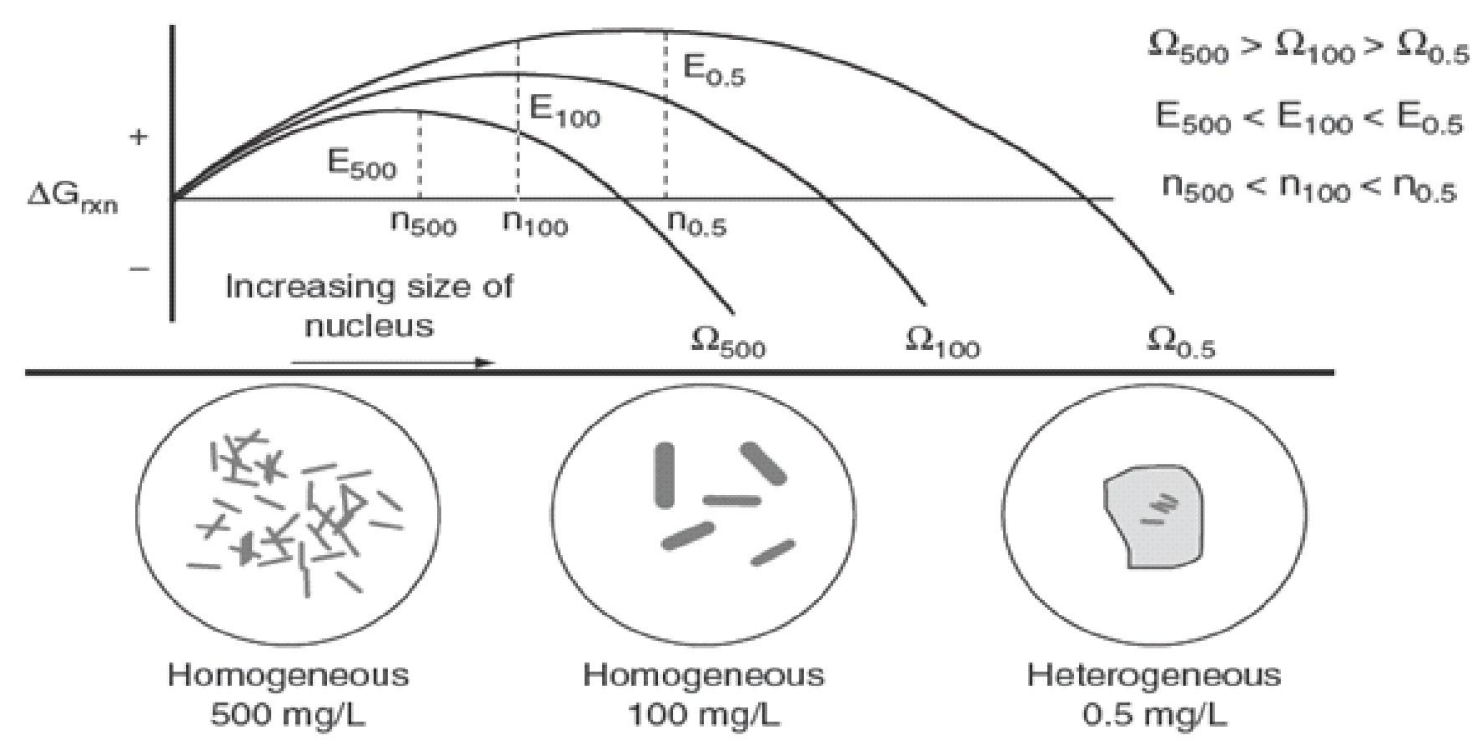

Fig.5. Saturation state affects nucleation of the $\mathrm{Pb}$-phosphate mineral pyromorphite in the presence of apatite. $i=$ saturation state, $\mathrm{E}=$ activation ener gy at different saturation states, $\mathrm{n}=$ crystal size at different saturation states (Source: Lower et al., 1998).

adsorption in the $\mathrm{pH}$ range where both organic chemicals and CNTs are not dehydrogenated. Therefore, it is essential to identify the contribution of different adsorption mechanisms at a given environmental condition. No good methods have been proposed and developed to study and separate the contribution of different mechanisms.

Role of organic matter in adsorption: In a typical soilwater system, natural organic matter (NOM) presents as two main forms. (1) NOM presents as solid phase such as precipitated humic acid and organomineral complex (humin). The adsorption of organic chemicals on these NOMs could decrease the mobility and bioavailability of organic chemicals. (2) NOM exists as dissolved organic matter in aqueous phase. The interaction between organic chemicals and dissolved NOM could enhance the solubility of organic chemicals, decrease their adsorption on solid particles, and possibly increase their environmental risk (Chiou et al., 1986; Pan et al., 2007; Pan et al., 2008). The interaction between aqueous NOM 


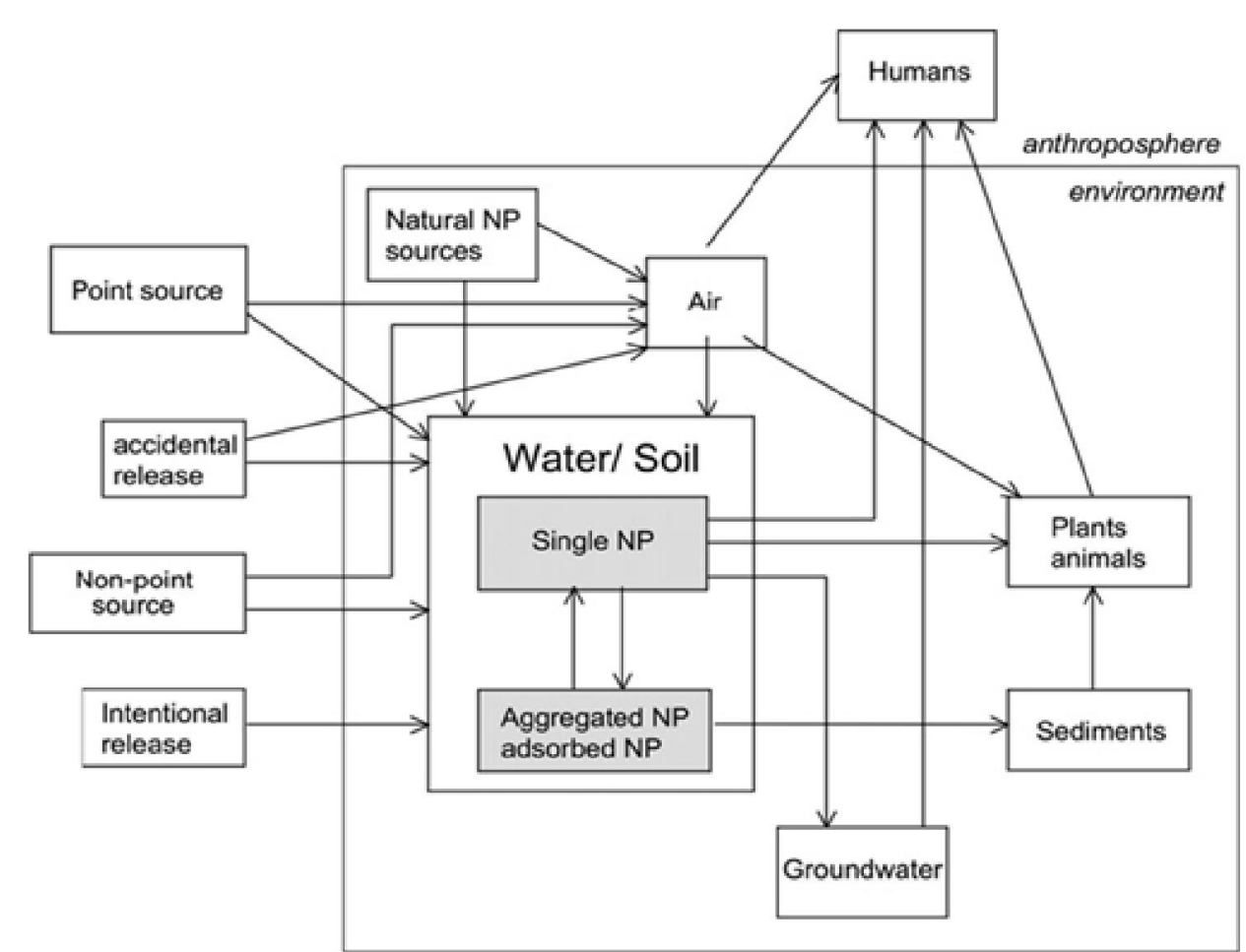

Fig. 6. Nanoparticle pathways from the anthropospher e into the soil environment (Source: Nowack and Bucheli, 2007).

and organic chemicals has not been well investigated in current studies. As indicated in Fig. 10, at low NOM concentrations, the adsorption of organic chemicals on MNPs may be increased because of the dispersion (for both CNTs and inorganic NPs) or NOM coating (for inorganic NPs). However, as NOM concentration further increases, the adsorption of NOM on MNPs reaches saturation. In this case, the significant interaction between aqueous NOM and organic chemicals could result in decreased adsorption. Current studies applied limited NOM concentrations in the experimental design, and often reported a decreased adsorption of organic chemicals on CNTs ( Ji et al., 2009; Wang et al., 2009) or increased adsorption on oxide NPs (Iorio et al., 2008) with the addition of NOM.

E ffect of organic chemical adsorption: NPs dispersion by organic chemicals could decrease their aggregate size or even to individual particles, which may increase the penetration of NPs through bio-nonbio interface. Thus, NP toxicity may be increased. Organisms may also react with NPs and increase NP dispersion or dissolution. For example, bacterial activity may promote the dissolution of ions from NPs and increase the bioavailability of toxic elements. In this case, the risk from the released ions instead of NPs themselves increased. But natural organic coatings (environment-derived macromolecules) may protect NPs from biological activities and thus extend the existence of NPs in the environment. Then, the risk of NPs could be increased. Biologically derived macromolecules could form organic coatings on NP aggregates. The organic coating may facilitate the dispersion of NPs and thus increase their mobility, which may consequently increase NP environmental exposure and risk. On the other hand, the coated organic molecules may screen off NP toxic effects. Organisms may also digest the organic molecules. The bioactivities may strip the organic coating. NPs could reaggregate and settle down, which eliminate their toxic effects. However, organisms may also react with NP surface and promote the release of some toxic ions.

Nanoparticle stability: As particle size decreases, the ratio of surface-area-to volume increases. And as always for nanoparticles, surface sites may become dominant and may influence the particle structure, stability, properties, and reactivity. Because of the high specific surface areas of nanoparticles, surface free energy plays a very important role in nanoparticle stability. Navrotsky (2001) observed that the oxides of $\mathrm{Ti}, \mathrm{Al}$, and $\mathrm{Zr}$ have varying degrees of stability as their particle size changes, and that the particles do not always become more stable with increasing size in the nano-range. Nanoparticulate oxides can exist as different stable polymorphs at different size ranges. A nanoparticle may undergo a number of phase transformations during growth.

Nanoparticle mobility in soils: Particles in the colloidal size range and smaller are not affected by gravitational settling; rather, Brownian motion becomes far more important. In the porous media associated with soils, some special factors also need to be considered. First, soils have both macropores and micropores. The micropores, which are the very small pores that occur within the soil structure, consist of a network of humic materials and 


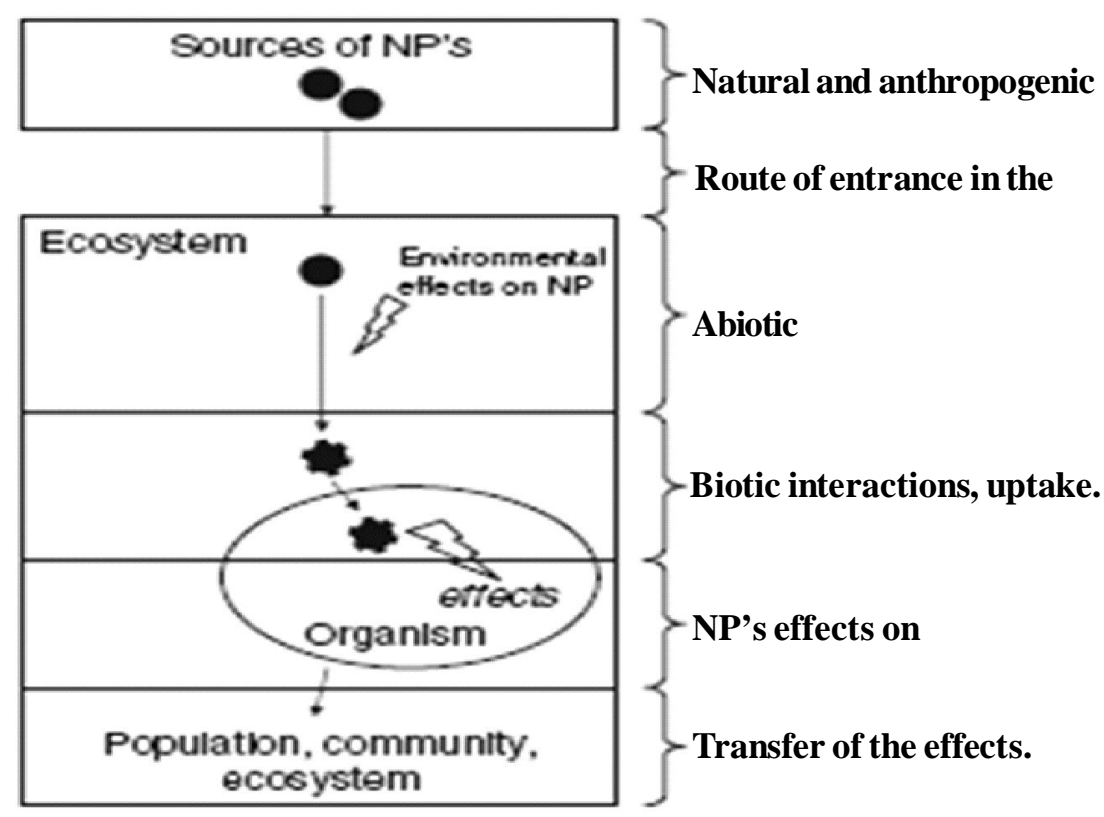

Fig. 7. The logical chain of events accounting for the toxicity of N P starts with the sources of N Ps and their entrance routes into the ecosystem. (Source: Navar ro et al., 2008).

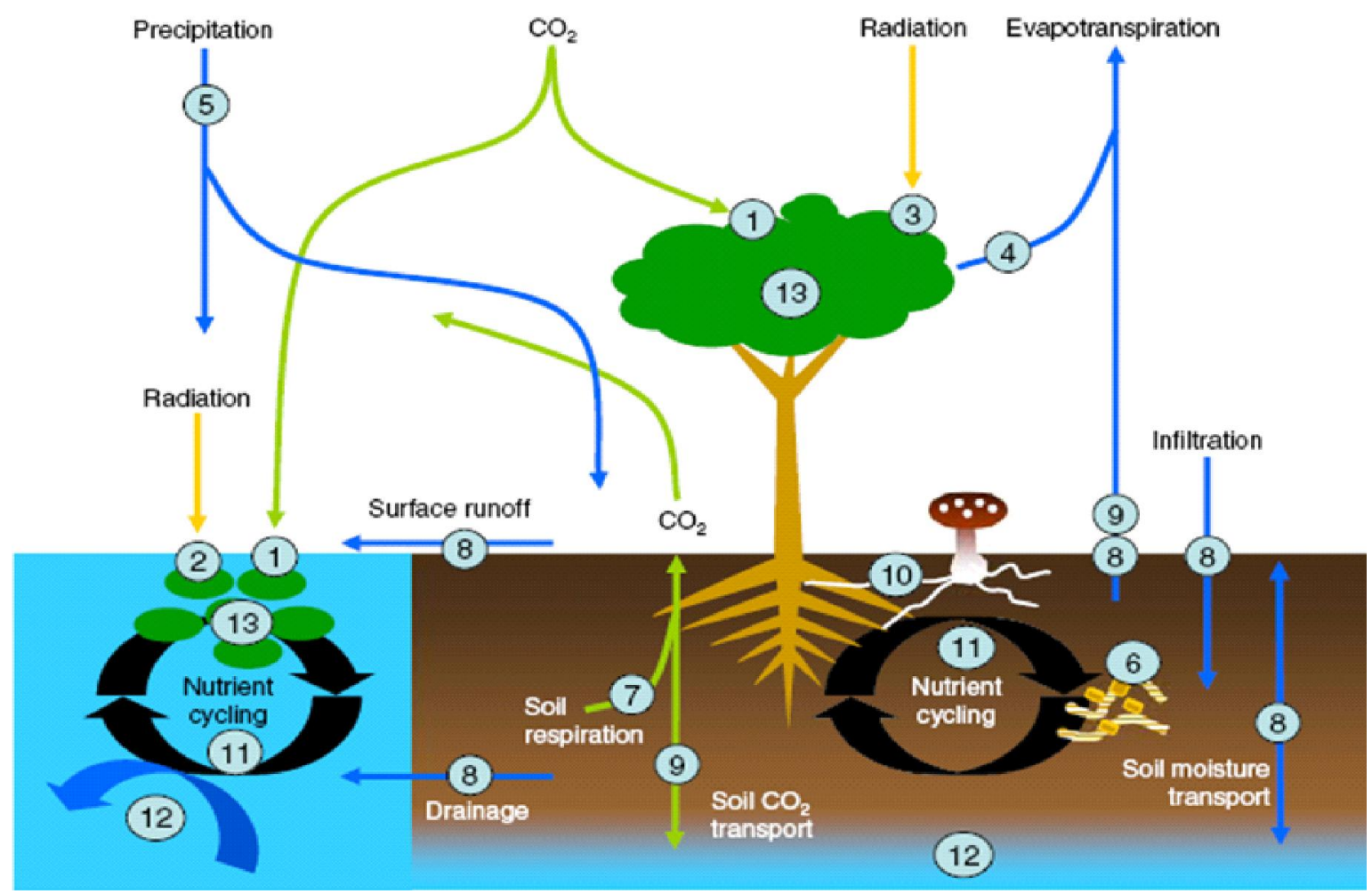

Fig. 8. Simplified scheme of some ter restrial and aquatic ecosystem processes. (Source: Navarro et al., 2008).

soil particles (e.g., Kretzschmar and Schafer, 2005).

Nanoparticles are small enough to fit into these micropore environments, and sequestration in the micropores can be expected to affect nanoparticle mobility. On the other hand, aggregates of nanoparticles may be too large to fit in the smaller pores, and may therefore be more likely to remain in the macropores. Due to high surface areas, nanoparticles have a strong potential to adsorb to soil and sediment particles. Nanoparticle sorption to nonmobile particles can be expected to inhibit mobility, whereas sorption to mobile colloids may enhance mobility. Additional factors that need to be considered include, for example, how both the shape of the nanoparticle and of the "collector" surfaces may affect adhesion of nanoparticles to surfaces.

Espinasse et al. (2007) showed that deposition of colloidal aggregates of $\mathrm{C} 60$ fullerene on saturated porous media increased with increasing ionic strength, the 


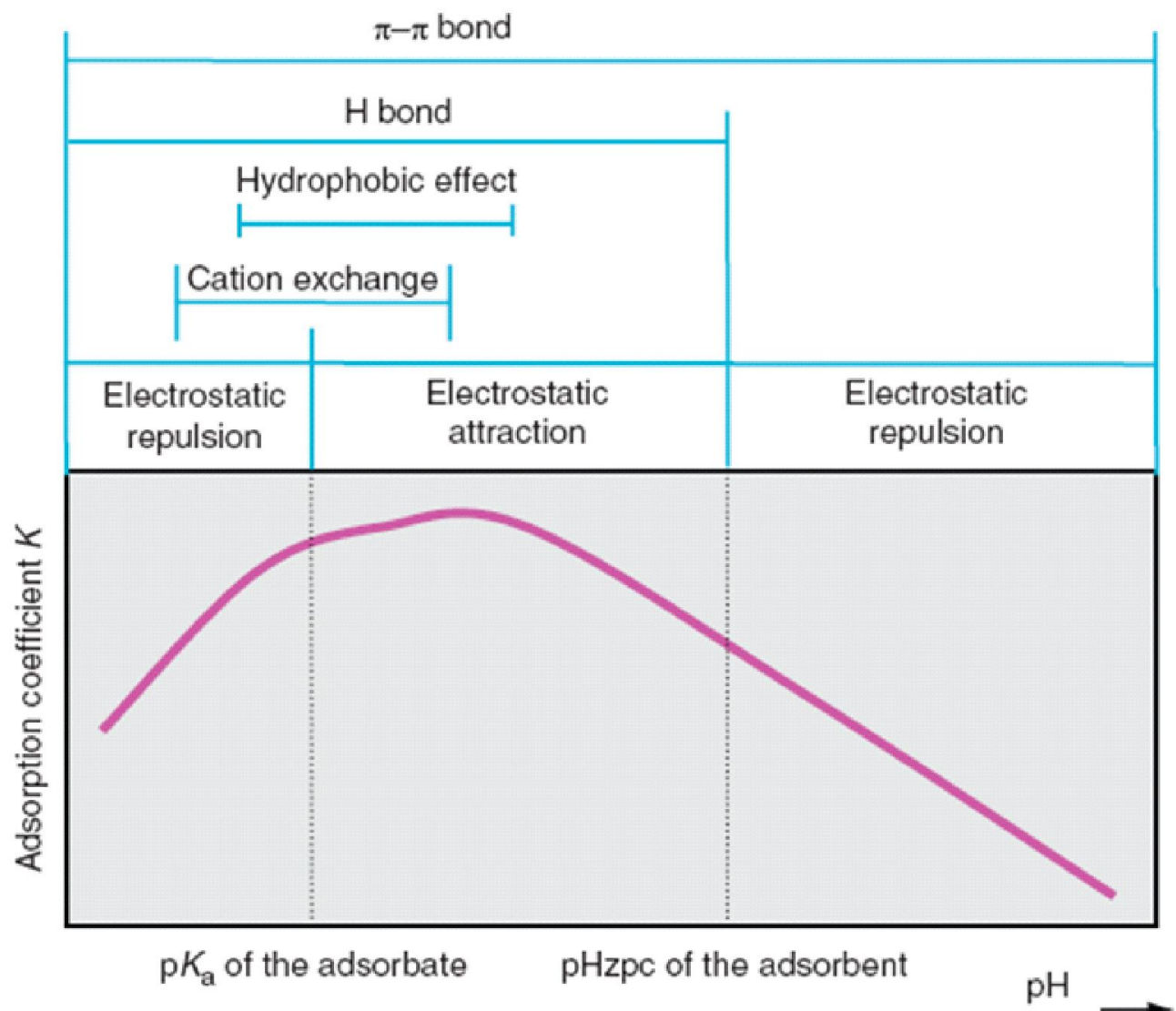

Fig. 9. Different adsor ption mechanisms at different pH s (Source: Zhang et al., 2010).

presence of polysaccharide-type organic matter, and lower Darcy velocities. On the other hand, low ionic strength and the presence of humic-like substances may decrease their retention on porous media. Chen et al. (2008) investigated unsaturated transport of $\mathrm{TiO}_{2}$ nanoparticles in systems that were specifically designed to minimize adherence to the surfaces of the porous media. Their results suggested that $\mathrm{TiO}_{2}$ nanoparticles may adsorb to the air-water interface, and that this interfacial phenomenon may affect their transport in the unsaturated zone.

\section{EFFECTS ON NANOPARTICLES}

Uptakeand toxicity: A consistent body of evidence shows that nano-sized particles are taken up by a wide variety of mammalian cell types, are able to cross the cell membrane and become internalized. The uptake on NP is size-dependent (Chithrani et al., 2006). Aggregation and

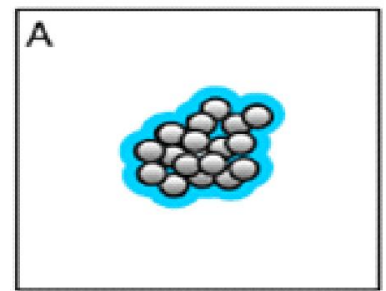

Aggregates of NPs

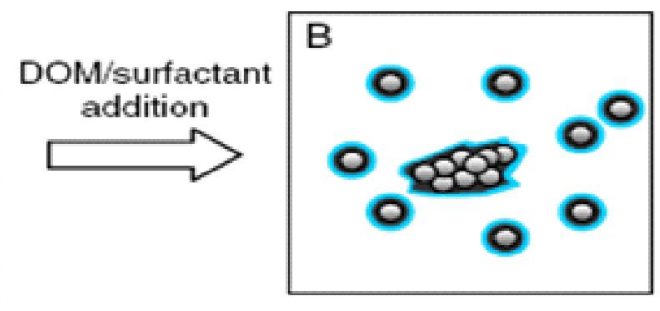

Dispersed NPs

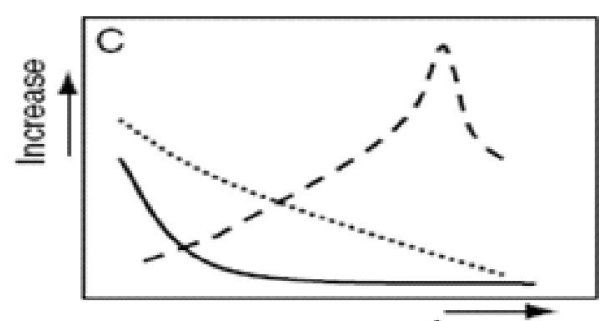

Increase

Concentration of DOM or surfactant

\begin{tabular}{|c|c|}
\hline O Single NP & ......... Zetá potential \\
\hline Adsorbed organic chemicals & - - Adsorption coefficient \\
\hline - NPs coated with DOM or surfactant & — Particle size of NP aggregates \\
\hline
\end{tabular}

Fig. 10. The role of dissolved organic matter (DOM) and surfactants in suspending MNPs and their adsorption for organic chemicals. Surface coated D O M /surfactant may decrease the zeta potential of M N Ps (C) and thus facilitate the dispersion of M NP aggregates (B). (Source: Pan and Xing, 2010). 


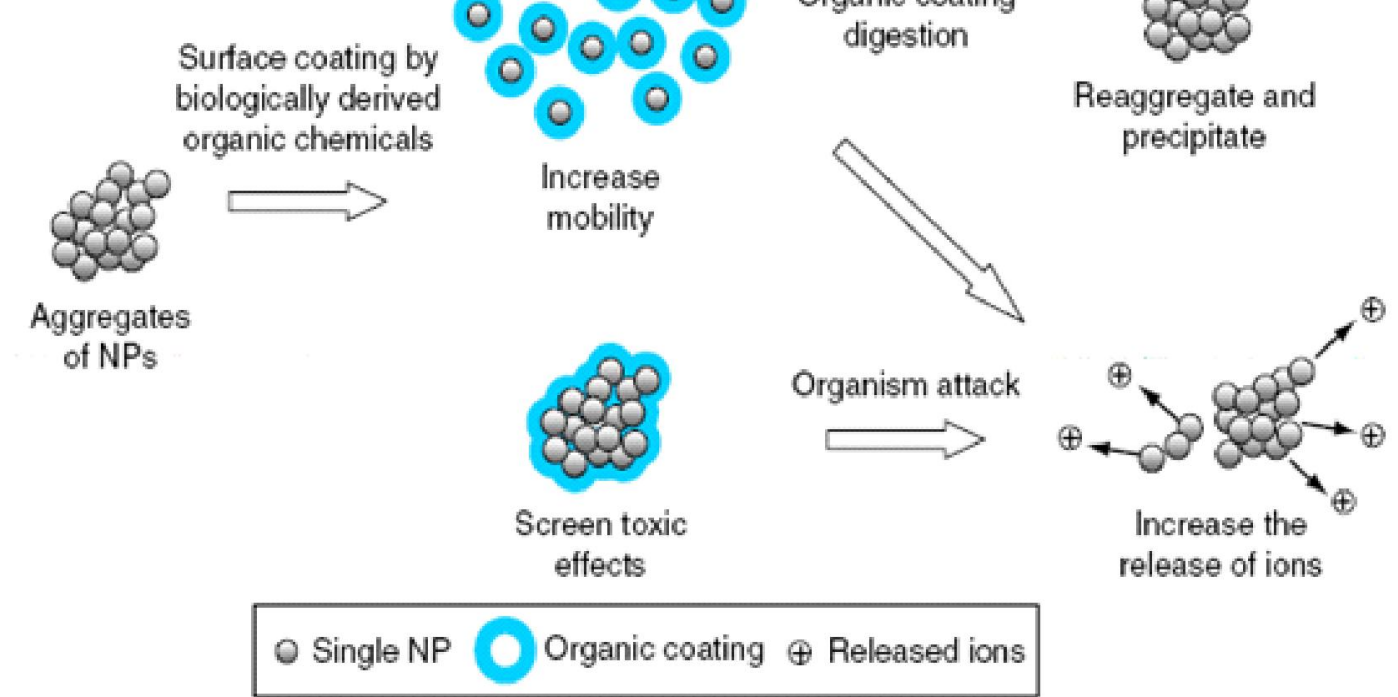

Fig. 11. Interaction of organism and N Ps. (Source: Pan and Xing, 2010).

size-dependent sedimentation onto the cells or diffusion towards the cell were the main parameters determining uptake (Limbach et al., 2005). The uptake occurs via endocytosis or by phagocytosis in specialized cells. One hypothesis is that the coating of the NPs by protein in the growth medium results in conformational changes of the protein structure, which triggers the uptake into the cell by specialized structures, limiting uptake to NPs below about $120 \mathrm{~nm}$ (Lynch et al., 2006). Within the cells NP are stored in certain locations (e.g. inside vesicles, mitochondria) and are able to exert a toxic response. The small particle size, a large surface area and the ability to generate reactive oxygen species play a major role in toxicity of NPs (Nel et al., 2006).

The mechanism for the antibacterial activities of nanoparticles is based upon contact mediated lipid peroxidation via production of reactive oxygen species (Neal, 2008). Interfacial forces, especially electrostatic, will control contact between nanoparticles and the bacterial membrane.

Attractive forces are generated between positively charged nanoparticles and negatively charged bacterial cells (1a). A repulsive force is generated between bacterial cells and negatively charged nanoparticles (1b). Processes which alter the surface charge of nanoparticles (1c) may indirectly alter the interaction between affected nanoparticles and bacterial cells. Once in contact with bacterial membranes, nanoparticles cause lethal cell damage by producing reactive oxygen species (ROS, 2d), eventually allowing ingress of nanoparticles into the periplasm/cytoplasm (2e). Exopolymers (2f) - secreted carbohydrates and proteins, may prevent nanoparticles or ROS contacting the cell membrane thus preventing cell damage. Following environmental release of nanoparticles, a number of processes may result in the formation of clumps as repulsive forces between the primary particles are reduced, these clumps of primary particles may fall out of suspension (3g); complexation by natural organic matter (3h) may also reduce the antibacterial effects of nanoparticles; inorganic surfaces such as mineral particles in soils may also prevent direct nanoparticle-bacterium contact by trapping nanoparticles at the surface ( $3 \mathrm{i}$ ).

Toxicity mechanisms have not yet been completely elucidated possible mechanisms for disruption of membranes or membrane potential, oxidation of proteins, genotoxicity, interruption of energy transduction, formation of reactive oxygen species, and release of toxic constituents (Fig. 14). The bacterial cell membrane is a semipermeable barrier that serves important cellular functions, such as regulation of material, transport, energy transduction, and intercellular communication.

Nanomaterials cause membrane damage through the generation of reactive oxygen species (ROS), which can oxidize double bonds on fatty acid tails of membrane phospholipids in a process known as lipid peroxidation. This increases membrane permeability and fluidity, making cells more susceptible to osmotic stress or hindering nutrient uptake (Cabiscol et al., 2000). Peroxidized fatty acids can trigger reactions that generate other free radicals, leading to more cell membrane and DNA damage. I nter actions among organisms, NPs and contaminants: The interaction of NPs with toxic, organic compounds can both amplify as well as alleviate the toxicity of the 


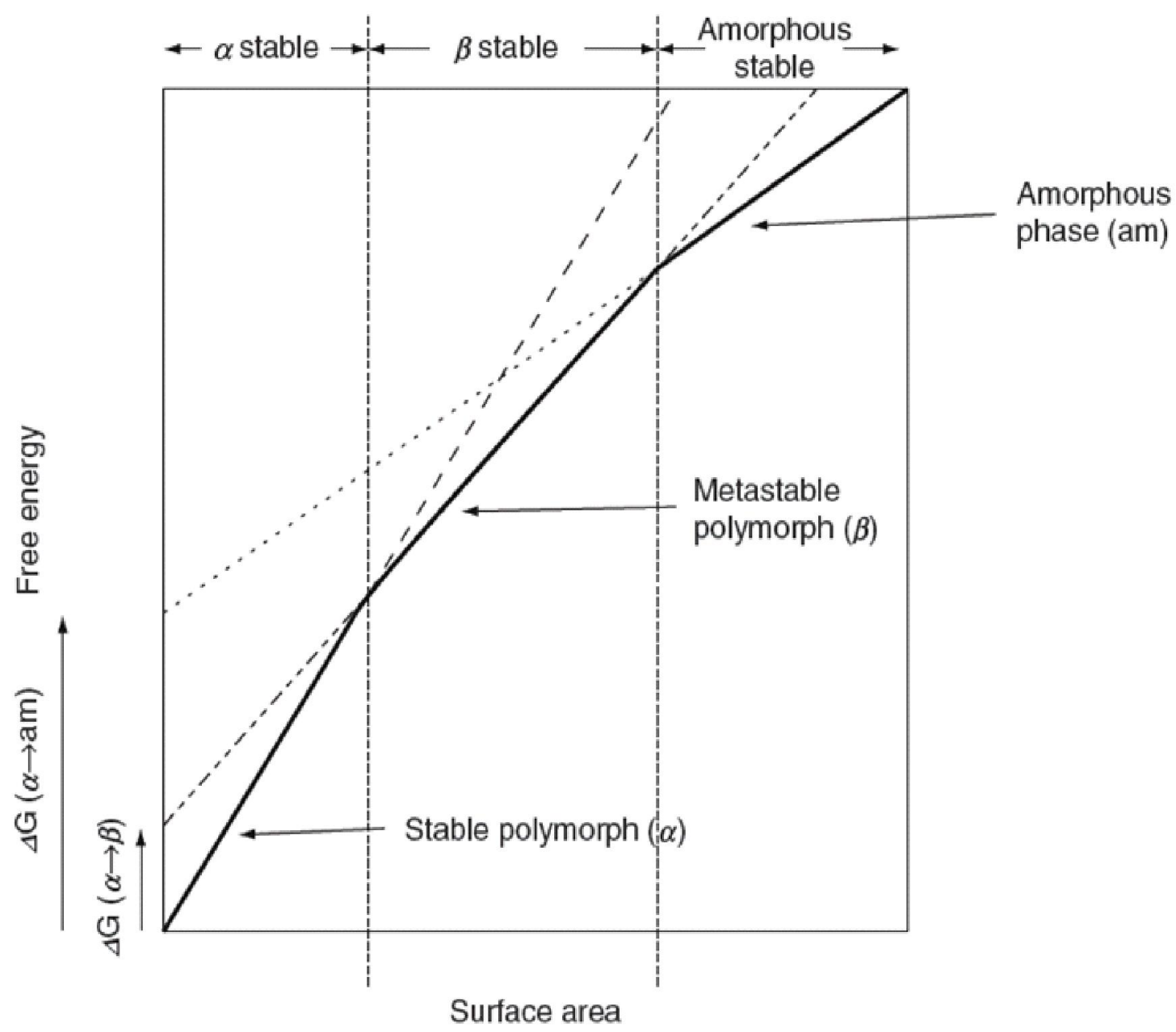

Fig. 12. The crossovers in free energy, and hence stability, for a nanoparticle system as a function of size (or surface area). The designation of stability (i.e., stable or metastable) refers to the bulk phases; they crossover for nanoparticles (Source: Navrotsky, 2001).

compounds. In contrast to harmful effects, NPs can therefore also have an advantageous role in the environment. The possible interactions in systems with organisms, NP and pollutants are (a) Adsorption and uptake of pollutant, (b) adsorption and uptake of nanoparticle, (c) adsorption (or absorption) of pollutants onto NPs and reduction in pollutant uptake by organisms and (d) adsorption of NPs with adsorbed (or absorbed) pollutant and possible uptake of pollutant-NPs (Fig. 15). The influence of pollutants on organisms is well studied (Fig. 15a) and the interaction with NPs alone have been described in sections above (Fig. 15b). In the ternary system organism pollutant NPs two possible ways of interaction are possible, Fig. 15c shows that the NP may adsorb or absorb the pollutant, therefore reducing its free concentration and hence reducing the toxicity of the pollutant. If the NPs with the adsorbed pollutants are taken up by the cells (Fig. 15d), then a toxic effect could be the consequence, either caused by the NP, the pollutant or in a synergistic way by both together. However, it could also be that no effect is observed if the bound pollutant is not bioavailable and the NP itself is not toxic. The strong sorption of organic compounds to black carbon was shown to be a dominant factor for the low and variable biota to sediment accumulation factors and the limited potential for microbial degradation (Cornelissen et al., 2005).

As for the indirect effects of ENPs, they are caused mainly by the physical restraints or the release of toxic ions (metal ENPs) or the production of ROS. Moreover, ENPs themselves may serve as pollutant carriers, thus enhancing or reducing the bioavailability of other toxic substances (Fig. 16). As a result of their remarkably high surface area to volume ratio and complexing capability, ENPs may adsorb pollutants, which might change the transport and bioavailability of both the ENPs and the pollutants in natural systems, and alter their toxic effects. Trace-metal ion speciation might be altered by NPs (especially oxide and oxide-coated NPs), therefore altering their bioavailability and potential toxicity (Gotovac et al., 2007; Hu et al., 2007; Wang et al., 2007). Some compounds present in environmental matrices might increase the NPs' stability (OM) and thus bioavailability, whereas others (salt ions) might foster the aggregation 

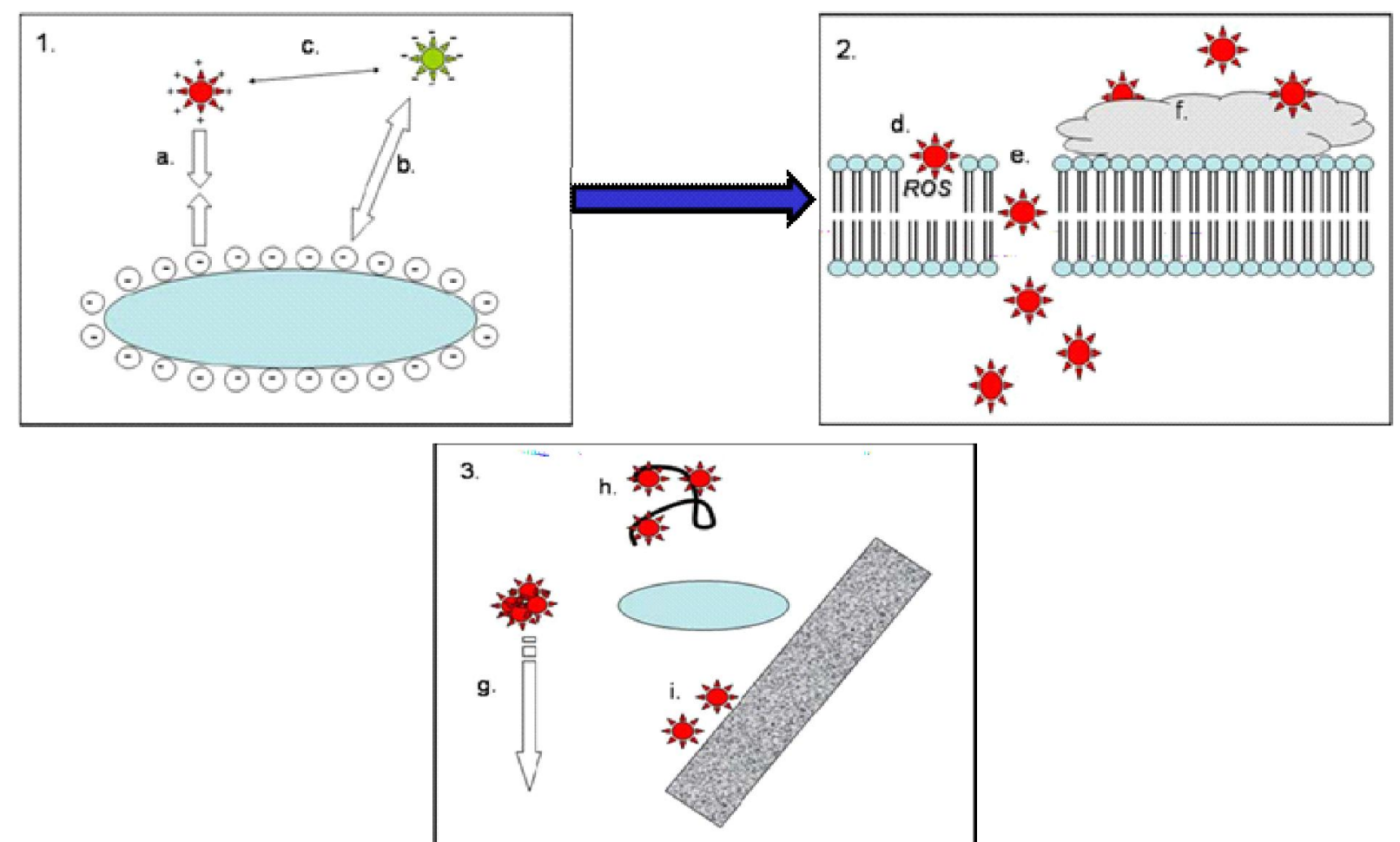

Fig. 13. Conceptual model for antibacterial activity of NPs and the effect of envir onmental exposure. (Source: Neal, 2008).

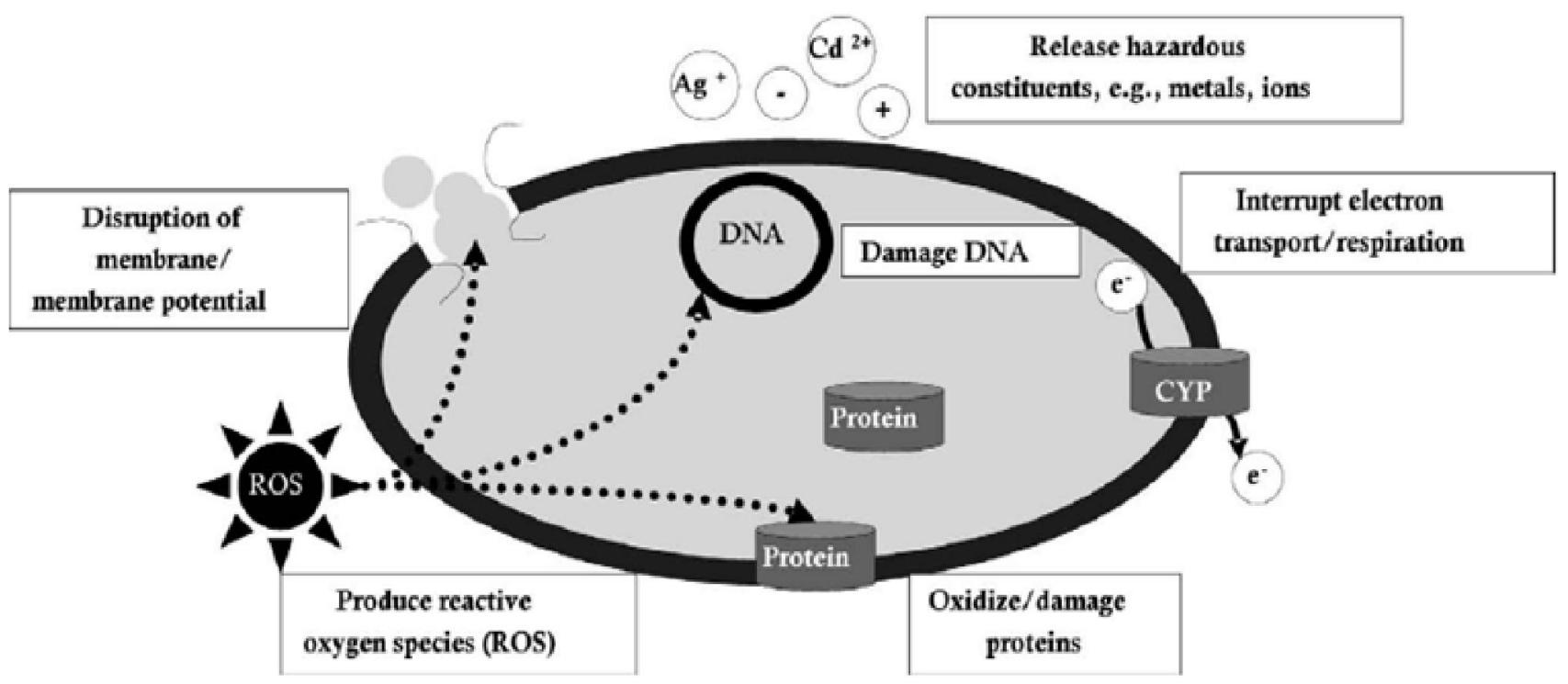

Fig.14. Possible mechanisms of nanomaterial toxicity to bacteria (Source: Klaine et al., 2008).

of NPs, thus reducing their bioavailability (represented as dotted arrows not entering organisms), or physically restraining $\mathrm{NP}-$ organism interactions. In other cases, NPs' bioavailability might be either increased or decreased (Navarro et al., 2008).

Fullerenes have only little impact on the soil microbial community and function, based on soil respiration, soil enzyme activity and changes in community structure (Tong et al., 2007). Bacterial cell walls show a physiological adaptation to the presence of fullerenes and they show a response in lipid composition and membrane phase behavior (Fang et al., 2007). Shah and
Belozerova (2009) have reported a statistically insignificant influence of the nanoparticles in the soil on the number of colony forming units of culturable bacteria, peak areas of methyl ester of fatty acids in the FAME profile or on the total soil community metabolic fingerprint. Silver nanoparticles damaged and pitted the cell wall of Escherichia coli and accumulated in the cell wall, leading to increased cell permeability and ultimately cell death (Soni and Bondi, 2004).

Interaction of NPS with plants: To date research on interaction of NP with plants is almost non-existent. One study reports the effect of aluminum oxide NP on root 


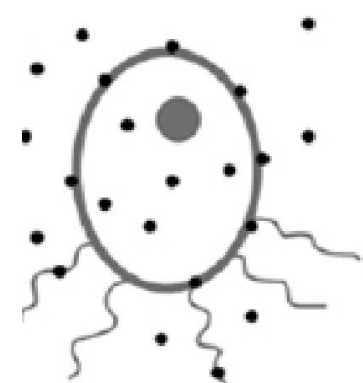

(a)

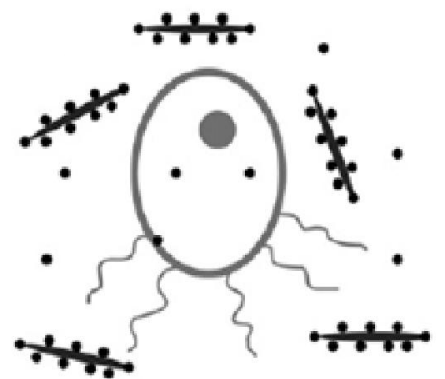

(c)

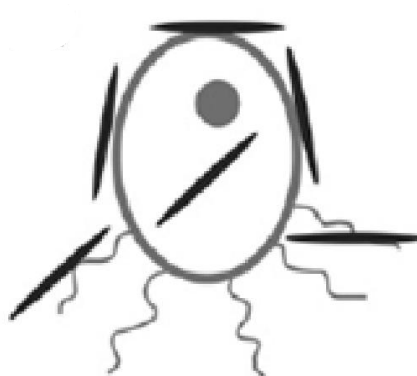

(b)

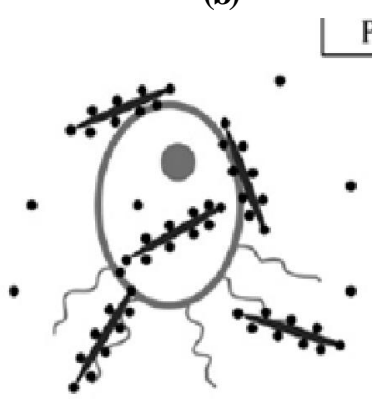

(d)

Fig. 15. Possible interactions of pollutants, NPs and organisms (Source: Nowack and Bucheli, 2007).

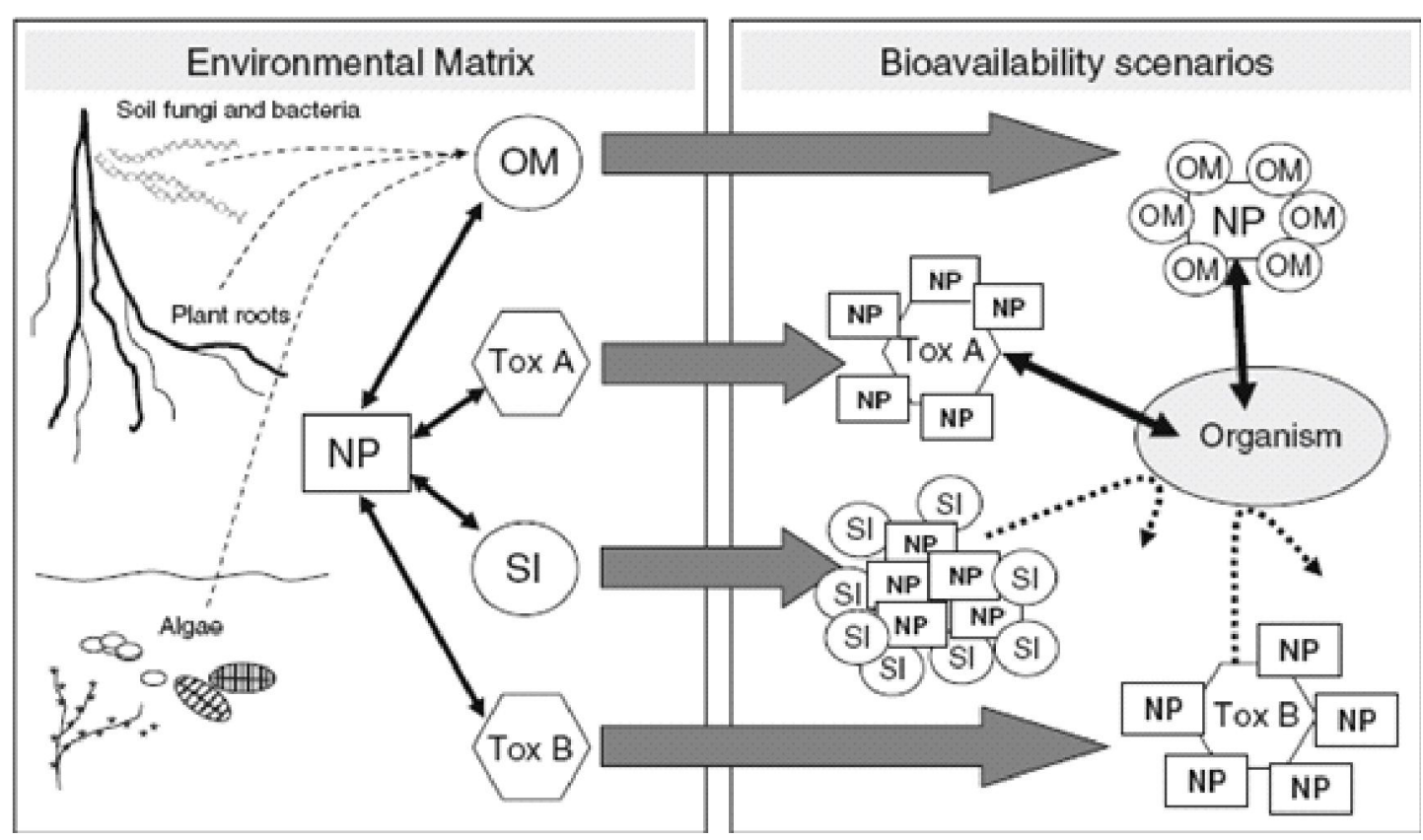

Fig. 16. Nanoparticles' (NPs) interactions with toxicants (Tox A and B), saltions (SI), and organic matter (OM) such as humic acids or compounds released by plants, fungi, bacteria, and al gae (Source: Navarro et al., 2008).

elongation in hydroponic studies (Yang and Watts, 2005). A slight reduction in root elongation was found in the presence of uncoated alumina NPs but not with NPs coated with phenanthrene. It was proposed that the surface characteristics of the alumina played an important role in phytotoxicity. The solubility of aluminum oxide is known to increase with decreasing particle size and modification of the surface by adsorbed compounds is known to affect the dissolution rate. Aluminum nanoparticles are commonly used in energetic formulations causing agglomeration leads to decreasing transport potential and bioavailability of nutrients in soil. Accumulation of $\mathrm{Fe}_{3} \mathrm{O}_{4}$ nanoparticles in pumpkin plants grown in sand was approximately $33 \%$ of that for pumpkin plants grown hydroponically. They also suggested that accumulation of $\mathrm{Fe}_{3} \mathrm{O}_{4}$ nanoparticles in plants is tissuespecific, with more accumulation in the leaves than in the stems. The majority of $\mathrm{Fe}_{3} \mathrm{O}_{4}$ nanoparticles was associated with the roots either absorbed into the roots or adsorbed on the surface, which raises some concern for contamination of root vegetables (Zhu et al., 2008). Toxic symptoms of $\mathrm{ZnO}$ nanoparticles and $\mathrm{Zn} 2+$ to the 

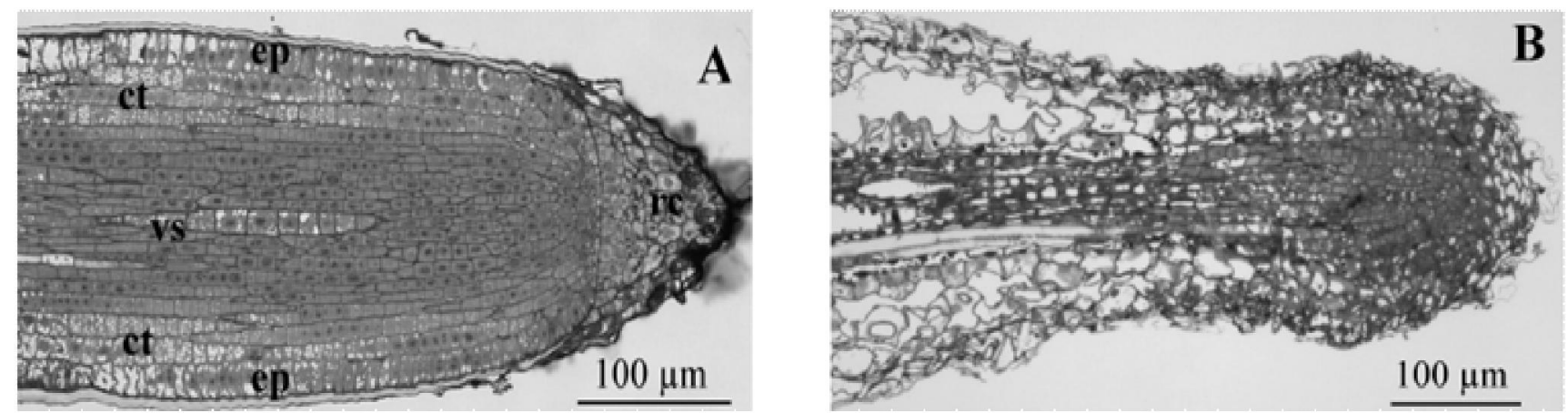

Fig. 17. Light microscopic observation of longitudinal sections of ryegrass primary root tips under treatments of control (A); 1000 $\mathrm{mg} \mathrm{L}^{-1} \mathrm{ZnO}$ nanoparticles (B); rc, rootcap; ep, epidermis; ct, cortex; vs, vascular cylinder.
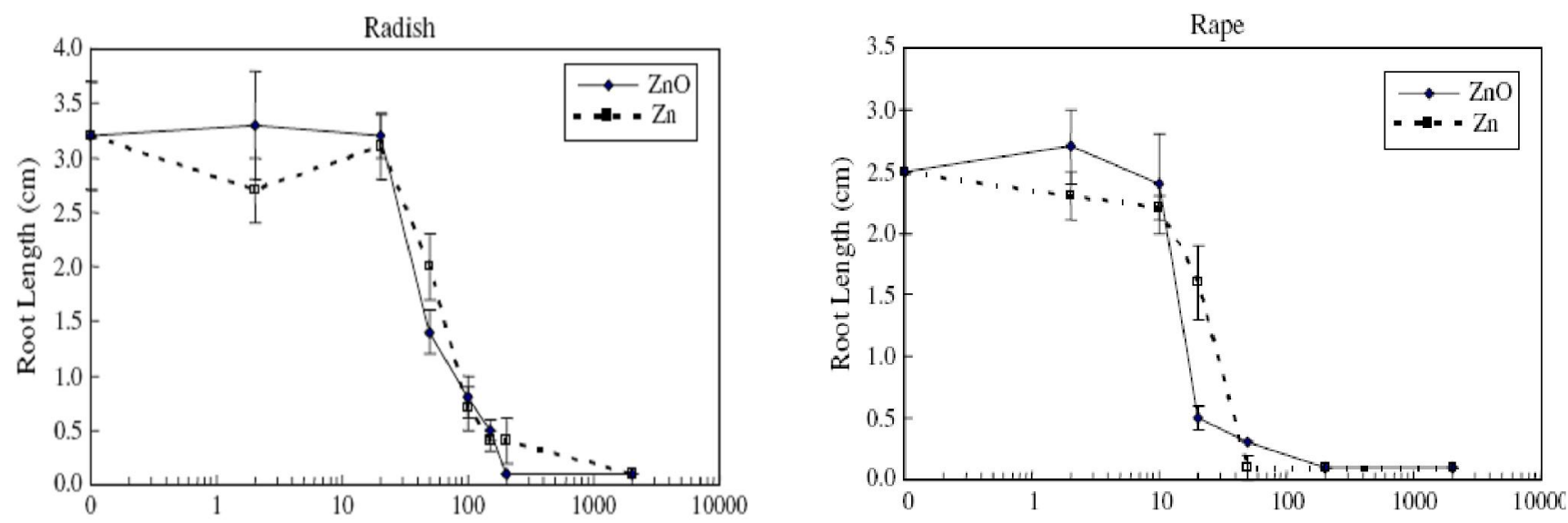

Fig. 18. D ose response curves of nano- $\mathrm{Zn}$ and nano- $\mathrm{ZnO}$ on root growth of radish and rape ryegrass. The values were given as mean SD (standard deviation) of triplicate samples with 10 seeds each.

ryegrass examined by Light microscopic (LM) of the longitudinally sectioned primary root tips (Fig. 17) (Lin and Xing, 2007). In the control, root tips developed very well with the usual three tissue systems (epidermis, cortex, and vascular cylinder) and an intact rootcap at the apex observed (Fig. 17A). However, shrank morphology of the root tips (Fig. 17B) indicates the severe impact of $\mathrm{ZnO}$ NPs and $\mathrm{Zn} 2+$ ions. In the presence of $1000 \mathrm{mg} \mathrm{L}^{-1}$ $\mathrm{ZnO} \mathrm{NPs}$ or $\mathrm{Zn}^{2+}$, the epidermis and rootcap were broken, the cortical cells were highly vacuolated and collapsed, and the vascular cylinder also shrank.

Dose response curves of nano- $\mathrm{Zn}$ and nano- $\mathrm{ZnO}$ suspensions on root growth of radish and rape are display in Fig. 18 (Lin and Xing, 2007). No significant root growth inhibition was observed under low concentrations (less than $10 \mathrm{mg} \mathrm{L}^{-1}$ for rape and $20 \mathrm{mg} \mathrm{L}^{-1}$ for radish). Root growth was clearly restricted with increasing concentration, and was almost terminated at $200 \mathrm{mg} \mathrm{L}^{-1}$.

Nano-Zn and nano-ZnO showed similar phytotoxicity at each of concentrations. Fifty percent root growth inhibitory concentrations $\left(\mathrm{IC}_{50}\right)$ of both nano- $\mathrm{Zn}$ and nano- $\mathrm{ZnO}$ were estimated to be near $50 \mathrm{mg} / \mathrm{L}$ for radish, and near $20 \mathrm{mg} \mathrm{L}^{-1}$ for rape. Radicles, after penetrating the seed coats, could contact the NPs directly. Therefore, root elongation of sensitive plant species would have a dose-dependent response.
Envir onmental risk assessment of NPs: Environmental exposure varies on the basis of conditions such as the way in which materials are handled in the workplace, how nanomaterials partition to various phases (e.g., water and air), the mobility of nanomaterials in each of these phases, their persistence, and the magnitude of the sources. A lot of research is currently devoted to these topics. This basic information about the behavior and toxicity is needed, but is not sufficient to allow for a realistic risk assessment of NPs in the environment. What is also needed is an evaluation of the expected quantities and concentrations of NPs in environmental systems. To date nothing is known about this issue, neither from an analytical point of view (e.g. actual measurements of NP sin the environment) nor with respect to theoretical or modeling studies. Only few products containing NPs are actually on the market, but this is expected to change rapidly in the next years as more and more nano-products are sold. It is therefore not only necessary to get an overview on current exposure, but also more important to anticipate future scenarios on the use of nano-products and exposure to released NP. As a starting point to risk assessment, exploring the sources and environmental pathways helps to identify relevant applications and situations where a subject deserving protection may face exposure to NP (Reijnders, 2006). 


\section{Conclusion}

There is currently a lot of attention being paid to the behavior and effects of engineered NP, but there is still only limited solid information. There is quite a vast amount of work being done with natural NP, e.g. soot and aquatic colloids, and the knowledge gained there will be of invaluable help in assessing the fate of engineered NP. Analytical methods developed for natural NP are now beginning to be applied to engineered NP. There is an almost complete lack of data on bioaccumulation, biotoxicity and biodegradation of NPs in soil environment and relevant species. There is also limited study of the weathering potential of both coatings and covalent surface modifications. Potential benefits of nanotechnology in the environment include use of NPs in bioremediation. For NPs, the public discussion predates the possibility of their analysis. Compared to conventional or other emerging contaminants, NP particles pose some new challenges for scientists. Many challenging questions remain unanswered, among them are (a) knowledge of soil NPs origin, occurrence, and its properties (b) methods to isolate NPs from soil (c) methods to measure NP concentrations in natural waters, sediments, soils, and organisms (d) NPs formation and their stability in the soil systems (e) processes of NP transformation, aggregation, and aging in terrestrial ecosystems (f) scientifically based conclusions on toxic effects of NPs on plants, microbes, and other soil living organisms. Thus, pluridisciplinary approaches are needed to address these stress.

\section{REFERENCES}

Banfield, J.F., and Zhang, H.Z.( 2001). Nanoparticles in the environment. In: Banfield, J.F., Navrotsky, A. (Eds.), Nanoparticles and the Environment, pp. 1-58.

Berner, R.A. (1980). Early Diagenesis: A Theoretical Approach. Princeton Series in Geochemistry. Princeton University Press, Princeton, NJ USA, 241 p.

Boxall, A.B.A., Chaudhry, Q., Jones, A., Jefferson, B., and Watts, C. D. (2008). Current and future predicted environmental exposure to engineered nanoparticles. Report to the Department of the Environment and Rural Affairs. Central Science Laboratory, York,UK.

Cabiscol, E., Tamarit, J., and Ros, J. 2000. Oxidative stress in bacteria and protein damage by reactive oxygen species. Int Microb., 3:3-8.

Chen, L.X., Sabatini, D. A., and Kibbey, T. C. G. (2008). Role of the air-water interface in the retention of $\mathrm{TiO} 2$ nanoparticles in porous media during primary drainage. Environ. Sci. Technol., 42, 1916-1921.

Chen, W., Duan, L., and Zhu, D. Q. (2007). Adsorption of polar and nonpolar organic chemicals to carbon nanotubes. Environ. Sci. Technol. 41: 8295-8300.

Chiou, C.T., Malcolm, R.L., Brinton, T. I., and Kile, D. E. (1986). Water solubility enhancement of some organic pollutants and pesticides by dissolved humic and fulvicacids.
Environ. Sci. Technol., 20: 502-508.

Chithrani, B.D., Ghazani, A.A., and Chan, W.C.W. (2006). Determining the size and shape dependence of gold nanoparticle uptake into mammalian cells. Nano Lett., 6:662668.

Cornelissen, G., Gustafsson, O., Bucheli, T.D., Jonker, M.T.O., Koelmans, A.A., and Van Noort, P.C.M. (2005). Extensive sorption of organic compounds to black carbon, coal, and kerogen in sediments and soils: mechanisms and consequences for distribution, bioaccumulation, and biodegradation Environ. Sci. Technol., 39: 6881-6895.

Eng, P.J., Trainor, T. P., Brown, G. E., Jr., Waychunas, G. A., Newville, M., Sutton, S. R., and Rivers, M. L. (2000). Structure of the hydrated a- $\mathrm{Al}_{2} \mathrm{O}_{3}(0001)$ surface. Science, 288: 1029-1033.

EPA. (2009). Nanotechnology White Paper. U.S. Environmental Protection Agency Report EPA 100/B-09/001, Washington DC 20460, USA.

Espinasse, B., Hotze, E. M., and Wiesner, M. R. (2007). Transport and retention of colloidal aggregates of C-60 in porous media: Effects of organic macromolecules, ionic composition, and preparation method. Environ. Sci. Technol., 41:7396-7402.

Fang, J., Lyon, D.Y., Dong, J., and Alvarez, P.J.J. (2007). Effect of a fullerene water suspension on bacterial phospholipids and membrane phase behavior. Environ. Sci. Technol., 41: 2636-2642.

Gotovac, S., Honda, H., Hattori, Y., Takahashi, K., Kanoh, H., and Kaneko, K. (2007). Effect of nanoscale curvature of single-walled carbon nanotubes on adsorption of polycyclic aromatic hydrocarbons. Nano. Lett., 7: 583-587.

Gottschalk, F., Sonderer, T., Scholz, R. W., and Nowack, B. (2009). Modeled environmental concentrations of engineered nanomaterials ( $\mathrm{TiO} 2, \mathrm{ZnO}, \mathrm{Ag}, \mathrm{CNT}$, fullerenes) for different regions. Environ. Sci. Technol., 43: 9216-9222.

Guzman, K.A.D., Taylor, M.R., and Banfield, J.F. (2006), Environmental risks of nanotechnology: national nanotechnology initiative funding, 2000-2004. Environ. Sci. Technol., 40: 1401-1407.

Hochella, M.F. Jr., Lower, S.K., Maurice, P.A., Penn, R.L., Sahai, N., Sparks, D.L. and Twining, B.S. (2008). Nanominerals, mineral nanoparticles and Earth chemistry. Science, 21: 1631-1635.

Hu, C.G., Yang, C.H., and Hu, S.S. (2007). Hydrophobic adsorption of surfactants on water-soluble carbon nanotubes, a simple approach to improve sensitivity and antifouling capacity of carbon nanotubes-based electrochemical sensors. Electrochim., $9:$ 128-134.

Iorio, M., Pan, B., Capasso, R., and Xing, B. S. (2008). Sorption of phenanthrene by dissolved organic matter and its complex with aluminum oxide nanoparticles. Environ. Pollut., 156: 1021-1029.

Ji, L. L., Chen, W., Zheng, S. R., Xu, Z. Y., and Zhu, D. Q. (2009). Adsorption of sulfonamide antibiotics to multiwalled carbon nanotubes. Langmuir, 25: 11608-11613.

Klaine, S. J., Alvarez, P. J. J., Batley, G. E., Fernandes, T. F. Handy, R. D., Lyon, D. Y., Mahendra, S., McLaughlin, M. J., and Lead, J. R. (2008). Nanomaterials in the environment: Behavior, fate, bioavailability, and effects. Environ. Toxicol. Chem., 27:1825-1851. 
Kretzschmar, R. and Schafer, T. (2005). Metal retention and transport on colloidal particles in the environment. Elements, 1: 205-210.

Limbach, L.K., Li, Y., Grass, R.N., Brunner, T.J., Hintermann, M.A., Muller, M., Gunther, D. and Stark, W.J. (2005). Oxide nanoparticle uptake in human lung fibroblasts: effects of particle size, agglomeration, and diffusion at low concentrations. Environ. Sci. Technol., 39 : 9370-9376.

Lin, D.H., and Xing, B.S. (2007). Phytotoxicity of nanoparticles: Inhibition of seed germination and root growth. Environ Pollut., 150 : 243-250.

Lower, S. K., Maurice, P. A., Traina, S. J., and Carlson, E. H. (1998). Aqueous $\mathrm{Pb}$ sorption by hydroxylapatite: Applications of atomic force microscopy to dissolution, nucleation, and growth studies. American M ineralogist, 83: 147-158.

Lynch, I., Dawson, K.A., and Linse, S. (2006). Detecting cryptic epitopes created by nanoparticles. Sci. STKE ., 3: 14-34.

Madden, A.S., and Hochella, M.F.( 2005). A test of geochemical reactivity as a function of mineral size: manganese oxidation promoted by hematite nanoparticles. G eochim. Cosmochim. Acta., 69 : 389-398.

Maurice, P. A., and Hochella, M. F. (2009). Nanoscale particles and processes: A new dimension in soil science. Adv. Agron. 100: 123-153.

Maurice, P.A., and Hochella, M.F. (2008). Nanoscale particles and processes: a new dimension in soil science. Adv. Agron., $100: 124-153$.

Maynard, A.D., Kouri, J.B., Ramirez, J.T., and Yacaman, M.J. (2006). Safe handling of nanotechnology. N ature, 444:267-69.

Murr, L.E., Soto, K.F., Esquivel, E. V., Bang, J. J., Guerrero, P. A., Lopez, D. A., and Ramirez, D.A. (2004). Carbon nanotubes and other fullerene-related nanocrystals in the environment: A TEM study. J. Mater. Sci., 56: 28-31.

Navarro, E. Baun, A., Behra, R., Nanna B.H., N.B.J., Miao, Ai-Jun., Quigg, A., Peter H. Santschi, P.H., and Sigg, L. (2008). Environmental behavior and ecotoxicity of engineered nanoparticles to algae, plants, and fungi. E cotoxicology, 17: 372-386.

Navrotsky, A. (2001). Thermochemistry of nanomaterials. In "Nanoparticles and the Environment. Reviews in Mineralogy and Geochemistry" (J. F. Banfield and A. Navrotsky, Eds.), Vol. 44, pp. 73-103. Mineralogical Society of America and Geochemical Society, Washington, DC.Chapter 3.

Neal, A.L. (2008). What can be inferred from bacteriumnanoparticle interactions about the potential consequences of environmental exposure to nanoparticles? E cotoxicology, 17: 362-371.

Nel, A., Xia, T., Madler, L., and Li, N. (2006). Toxic potential of materials at the nanolevel. Science, 311:622-627.

Nielsen, A.E. (1964). Kinetics of Precipitation, MacMillan, New York, $151 \mathrm{p}$
Nowack, B., and Bucheli, T.D. (2007) Occurrence, behavior and effects of nanoparticles in the environment. Environ Pollut., 150:5-22

Pan, B., and Xing, B. (2010). Manufactured nanoparticles and their sorption of organic chemicals. Advances in Agronomy, 108:137-181.

Pan, B., Ghosh, S., and Xing, B. S. (2007). Nonideal binding between dissolved humic acids and polyaromatic hydrocarbons. Environ. Sci. Technol ., 41: 6472-6478.

Pan, B., Ghosh, S., and Xing, B.S. (2008). Dissolved organic matter conformation and its interaction with pyrene as affected by water chemistry and concentration. Environ. Sci. Technol., 42: 1594-1599.

Reijnders, L. (2006). Cleaner nanotechnology and hazard reduction of manufactured nanoparticles. J. Clean. Prod., 14: 124-133.

Shah, V., and Belozerova, I. (2009). Influence of metal nanoparticles on the soil microbial community and germination of lettuce seeds. Water, Air, Soil Pollut., 197: 143-148.

Soni, I., and Bondi, S.B. (2004). Silver nanoparticles as antimicrobial agent: A case study on E. coli as a model for Gram-negative bacteria. J . Colloid Interf. Sci., 275: 17701782.

Theng, B.K.G. (2008). Clay-organic interactions. In, Chesworth, W. (ed), Encyclopedia of Soil Science. Springer, Dordrecht, pp 144-150.

Tong, Z., Bischoff, M., Nies, L., Applegate, B., and Turco, R.F. (2007). Impact of fullerene $\left(C_{60}\right)$ on a soil microbial community. Environ. Sci. Technol., 41: 2985-2991.

Wang, C.M., Baer, D.R., Amonette, J. E., Engelhard, M. H., Antony, J., and Qiang, Y. (2009). Morphology and electronic structure of the oxide shell on the surface of iron nanoparticles. J. Am. Chem. Soc., 131: 8824-8832.

Wang, Y., Wong, J.F., Teng, X.W., Lin, X.Z. and Yang, H. (2007). "Pulling" nanoparticles into water, phase transfer of oleic acid stabilized monodisperse nanoparticles into aqueous solutions of alphacyclodextrin. Nano. Lett., 7: 1555-1559.

Waychunas, G.A., Kim, C.S., and Banfield, J.F. (2005). Nanoparticulate iron oxide minerals in soils and sediments: unique properties and contaminant scavenging mechanisms. J. Nanopart. Res., 7: 409-433.

Yang, L., and Watts, D.J. (2005). Particle surface characteristics may play an important role in phytotoxicity of alumina nanoparticles. Toxicol. L ett., 158: 122-132.

Zhang, D., Pan, B., Zhang, H., Ning, P., and Xing, B. S. (2010). Contribution of different sulfamethoxazole species to their overall adsorption on functionalized carbon nanotubes. Environ. Sci. Technol., 44: 3806-3811.

Zhu, S.Q., Oberdorster, E., and Haasch, M.L. (2008). Toxicity of an engineerednanoparticle (fullerene, C60) in two aquatic species, Daphnia and fathead minnow. Marine Environ Res., 65: 5-9. 